\title{
VIII Encuentro Nacional de Medicina del Dormir: más fuerte que nunca
}

\author{
José Luis Carrillo-Alduenda $\bowtie$
}

Pasado Presidente, Academia Mexicana de Medicina del Dormir, AC. Fecha de recepción: 11-IX-2017; aceptado: 12-IX-2017

El pasado 17, 18 y 19 de agosto 2017 se llevó a cabo el VIII Encuentro Nacional de Medicina del Dormir y con la participación de ponentes nacionales e internacionales, investigadores y diferentes asociaciones se consolidó como el evento científico sobre Medicina del Dormir más importante de nuestro país.

El primer día, con 30 asistentes y 5 instructores, se impartió el taller titulado: «Diagnóstico, tratamiento y seguimiento simplificados de la apnea obstructiva del sueño del adulto", así, los concurrentes adquirieron las competencias para atender el trastorno de sueño más importante para la sociedad debido a su impacto en la salud pública.

Los días 18 y 19 de agosto, con el lema: «La medicina del sueño: una subespecialidad multidisciplinaria», 200 asistentes presenciales y 100 en línea, transcurrieron como jornadas académicas en las que profesores nacionales y extranjeros presentaron actualidades en las diferentes disciplinas involucradas en la Medicina del Dormir como: neurología, psiquiatría, neumología, psicología y otorrinolaringología, entre otras. Dentro del programa destacó la participación de la Dra. Leslie Katherine Vargas Ramírez de la Fundación Neumológica Colombiana y del Dr. Pablo Brockmann Veloso de la Pontificia Universidad Católica de Chile quienes aportaron sus conocimientos y experiencias en el manejo de los trastornos respiratorios del dormir en adultos y niños, respectivamente.

También se llevó a cabo el II Simposio Intersociedades de Sueño, con la participación de la Academia
Mexicana de Medicina del Dormir (AMMD) y la Sociedad Mexicana para la Investigación y Medicina de Sueño (SOMIMS), pero este año se agregó la Sociedad Chilena de Medicina de Sueño, fortaleciendo así los lazos con otras organizaciones y fomentando colaboraciones.

La investigación es un pilar fundamental en el trabajo de la AMMD, de tal manera, se presentaron 24 trabajos libres con temas variados en medicina de sueño básica, clínica y epidemiológica. Destacaron los trabajos: «Cambios en el sueño resultantes de la interacción genes-ambiente en Drosophila melanogaster» de la Facultad de Psicología de la Universidad Nacional Autónoma de México premiado como mejor trabajo oral; y «Asociación entre el volumen faríngeo y el índice de apnea de hipopnea: diferencias de género" de la Clínica SOMNOSCAN como mejor póster.

Con este VIII Encuentro Nacional de Medicina del Sueño como marco se llega al término de una exitosa administración. La única dirección posible para la AMMD es crecer y fortalecerse para permanecer como la organización científica en Medicina de Sueño más importante de México.

\section{$\triangle$ Correspondencia:}

Dr. José Luis Carrillo-Alduenda

Correo electrónico: jlcarrillo14@hotmail.com

El autor declara no tener conflicto de intereses. 